\title{
Far Lateral Approach (Transcondylar, Transtubercular) for Bypass and Trapping of a Ruptured, Dissecting PICA Aneurysm
}

\author{
Andrew S. Venteicher ${ }^{1}$ Ezequiel Goldschmidt ${ }^{1}$ Paul A. Gardner ${ }^{1}$ \\ ${ }^{1}$ Department of Neurological Surgery, University of Pittsburgh \\ Medical Center, Pittsburgh, Pennsylvania, United States \\ Address for correspondence Paul A. Gardner, MD, Department of \\ Neurological Surgery, 200 Lothrop Street, Suite B400, University of \\ Pittsburgh Medical Center, Pittsburgh, PA 15213, United States \\ J Neurol Surg B 2021;82(suppl S1):S41-S42. \\ (e-mail: gardpa@upmc.edu).
}

\begin{abstract}
Keywords

- extracranialintracranial bypass

- aneurysm trapping

- far lateral approach

- transcondylar transtubercular approach

- jugular tubercle

Aneurysms of the posterior circulation pose a unique challenge due to higher rupture rates, higher recurrence rates following endovascular treatment, and extended open cranial base approaches required to reach the ventrally located brainstem circulation. While endovascular therapy has made tremendous strides in successful treatment for most posterior circulation aneurysms, open microscopic approaches remain essential in specific circumstances. Here, we present a case of a patient who presented with acute, severe headache, and sixth nerve palsies, and who was found to have hydrocephalus and a dissecting aneurysm at the anterolateral medullary segment of the posterior inferior cerebellar artery (PICA). Interestingly, this patient had a history of alpha- 1 antitrypsin deficiency that has been linked with spontaneous aortic and cervical arterial dissections. The fusiform geometry of the dissecting aneurysm was deemed suboptimal for endovascular treatment, so an open microsurgical approach for occipital artery to PICA bypass and aneurysm trapping was planned. Because this patient had cerebral edema in the setting of a ruptured aneurysm and hydrocephalus, a far lateral craniotomy combined with drilling of the occipital condyle and jugular tubercle was critical to enhance exposure of the first segment of the PICA and to minimize brain retraction. In this video, we highlight the key steps and nuances for harvest of the occipital artery, achieving control of the extracranial vertebral artery, performing the transcondylar and transtubercular far lateral approach, and bypass with trapping technique for these challenging posterior circulation aneurysms. The link to the video can be found at: https://youtu.be/dqgblwX6t0Q.
\end{abstract}

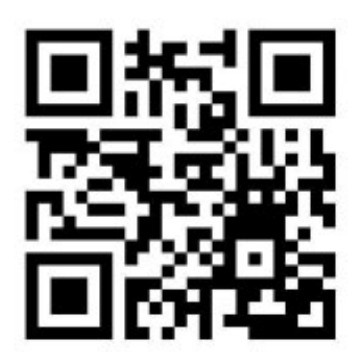

received

March 30, 2019 accepted after revision September 29, 2019 published online July 1,2020

\section{Conflict of Interest}

P.A.G. reports other from SPIWay, LLC, outside the submitted work.

\section{Acknowledgments}

The authors thank the Rhoton Collection for access to anatomic photographs used in this video.

www.thieme.com/skullbasevideos

www.thieme.com/jnlsbvideos

(c) 2020. The Author(s).

This is an open access article published by Thieme under the terms of the Creative Commons Attribution-NonDerivative-NonCommercial-License, permitting copying and reproduction so long as the original work is given appropriate credit. Contents may not be used for commercial purposes, or adapted, remixed, transformed or built upon. (https://creativecommons.org/ licenses/by-nc-nd/4.0/)

Georg Thieme Verlag KG, Rüdigerstraße 14, 70469 Stuttgart, Germany 




Fig. 1 Angiography demonstrating occipital artery to PICA bypass and trapping of a dissecting PICA aneurysm. Preoperative magnified view (A) of the left vertebral angiogram shows a dissecting aneurysm along the anterolateral segment of PICA with intimal flap (blue arrow). Lateral view of the left vertebral angiogram (B) before and (C) after aneurysm trapping (red circles). (D) Intraoperative left common carotid angiogram demonstrates a patent occipital artery to PICA bypass. PICA, posterior inferior cerebellar artery. ECA, External Carotid Artery.
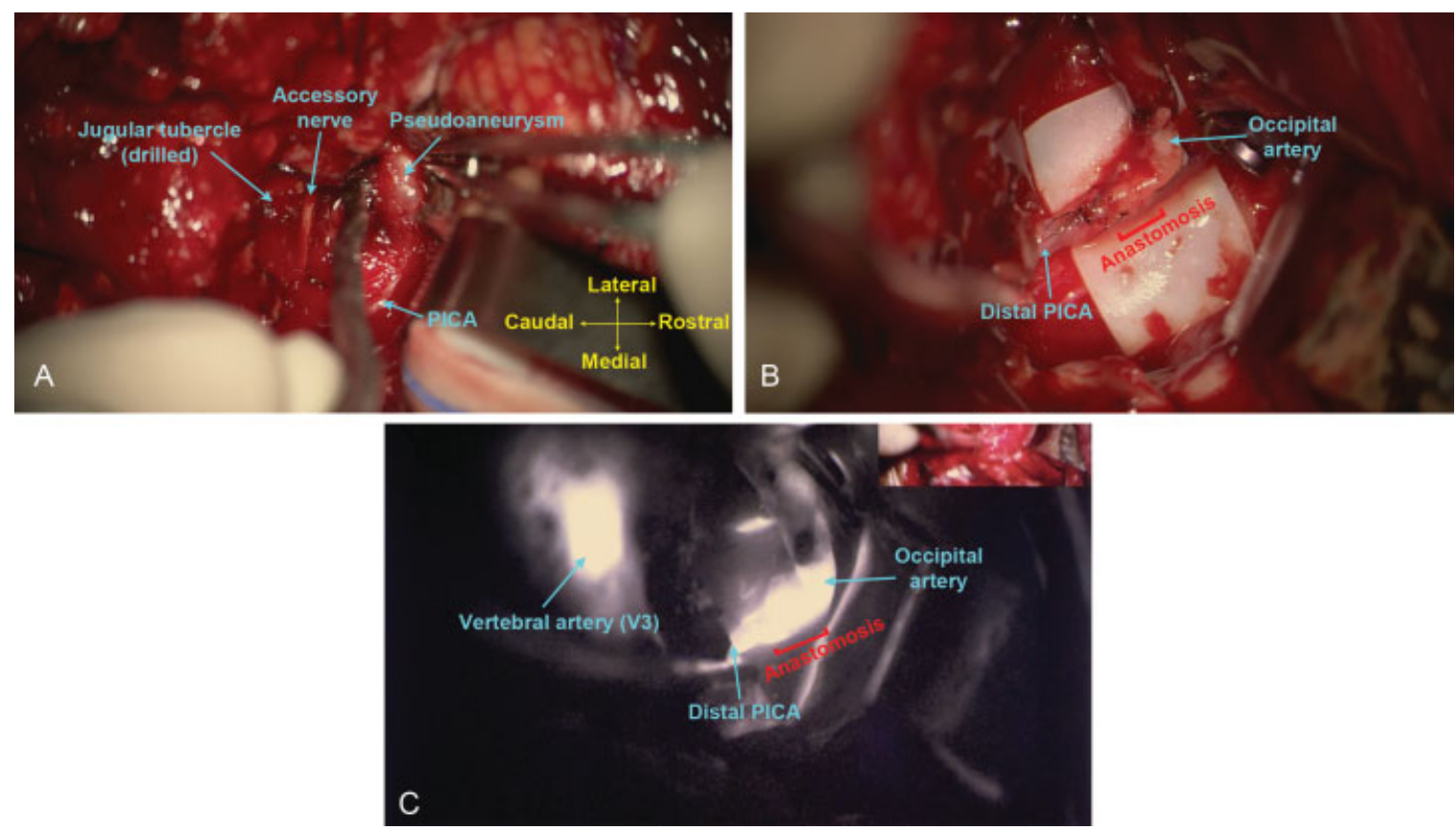

Fig. 2 Key microsurgical steps in the left-sided occipital to PICA bypass and PICA aneurysm trapping. (A) Expanded intradural exposure of the distal PICA and dissecting aneurysm after transcondylar and transtubercular drilling. (B) Microscopic view of occipital artery to PICA anastomosis and aneurysm trapping. (C) ICG (indocyanine green) angiography run showing patent site of anastomosis from occipital artery to the distal PICA territory. PICA, posterior inferior cerebellar artery. 